Family Profile No. 19, 2018

\title{
Living with a Sibling or Roommate in Older Adulthood, 1990 \& 2016
}

Author: Huijing Wu

A growing share of adults, including those in middle and later life, are unmarried. Many of these older adults either live alone or cohabit with an intimate partner, but some reside with either a sibling or a roommate. Drawing on 1990 Census and 2016 American Community Survey data, this profile examines patterns of sibling co-residence and living with a roommate among adults aged 50-74.

Older Adults Living with a Sibling or Roommate, 1990 \& 2016

- There has been a dramatic increase in the total number of adults aged 50-74 living with either a sibling or an unrelated roommate in the same household. In 2016, 3.2 million older adults were living with a sibling or roommate-nearly triple the numbe from 1990 (1.2 million).

- The percentage increase from 1990 to 2016 in the number of people living with a sibling or unrelated roommate was greater for men $(+213 \%)$ than women $(+137 \%)$.

- The numbers of older men and women living with a sibling were higher than those living with an unrelated roommate in 1990 and 2016.
Figure 1. Older Adults Living with a Sibling or Roommate, 1990 \& 2016 - Sibling Roommate

\section{$3,216,524$}

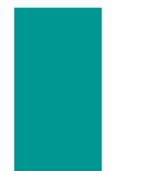

$1,561,496$

$1,655,028$

$1,198,472$

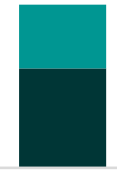

Total

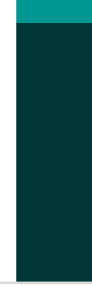

Men

1990

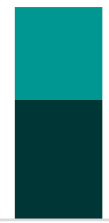

Men

2016

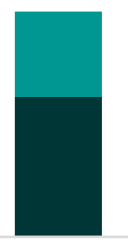

Women

Source: NCFMR analyses of U.S. Census Bureau, Decennial Census, 1990; U.S. Census Bureau, American Community Survey, 2016 (IPUMS)

Marital Status

- In 1990, the most common marital status for older adults living with a sibling or roommate was never married (42\%), followed by divorced (36\%) and widowed (23\%). In 2016, the proportion of divorced older adults (47\%) eclipsed the never married (42\%), with widowhood remaining the least common (11\%).

- Although divorce was more common for both men and women in 2016, the proportion divorced increased more among women, rising from $30 \%$ in 1990 to $47 \%$ in 2016.

- The percentage of older adults living with a sibling or unrelated roommate who were widowed decreased by nearly half between 1990 and 2016, regardless of gender. However, a larger share of women than men living with a sibling or roommate were widowed (15\% versus $6 \%$ in 2016).

Figure 2. Older Adults Living with a Sibling or Roommate by Marital Status, 1990 \& 2016

- Divorced/separated $\square$ Widowed $\square$ Never married/single

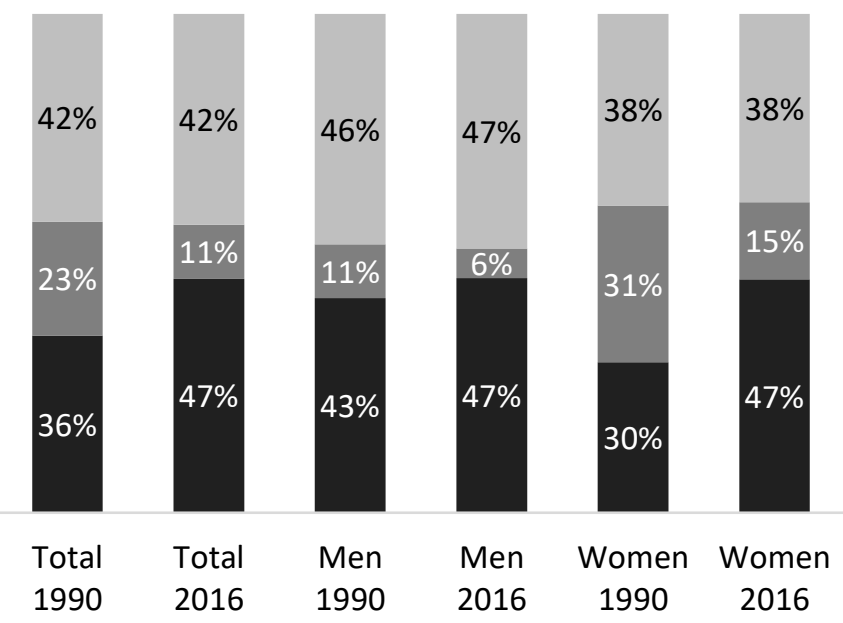

Source: NCFMR analyses of U.S. Census Bureau, Decennial Census, 1990; U.S. Census Bureau, American Community Survey, 2016 (IPUMS) 
- Older adults living with a sibling were most often never married ( $55 \%$ for men and $43 \%$ for women). Further, larger shares of those living with a sibling were never married compared to those living with a roommate (37\% for men and $30 \%$ for women).

- Older adults living with a roommate were most often divorced (56\%).

\section{Poverty Status by Gender}

- About $18 \%$ of older adults living with either a sibling or a roommate were at or below the poverty level in 2016.

- Poverty levels were over three times higher for older adults residing with a roommate than a sibling.

- Among older adults living with a sibling, men had a slightly higher share than women at or below the poverty line

- $\quad(10 \%$ and $8 \%$, respectively). In contrast, among those living with a roommate, women had higher shares in poverty than men (31\% and $33 \%$, respectively).
Figure 3. Marital Status by Older Adults Living with a Sibling or Roommate by Gender, 2016

Divorced/separated Widowed Never married/single

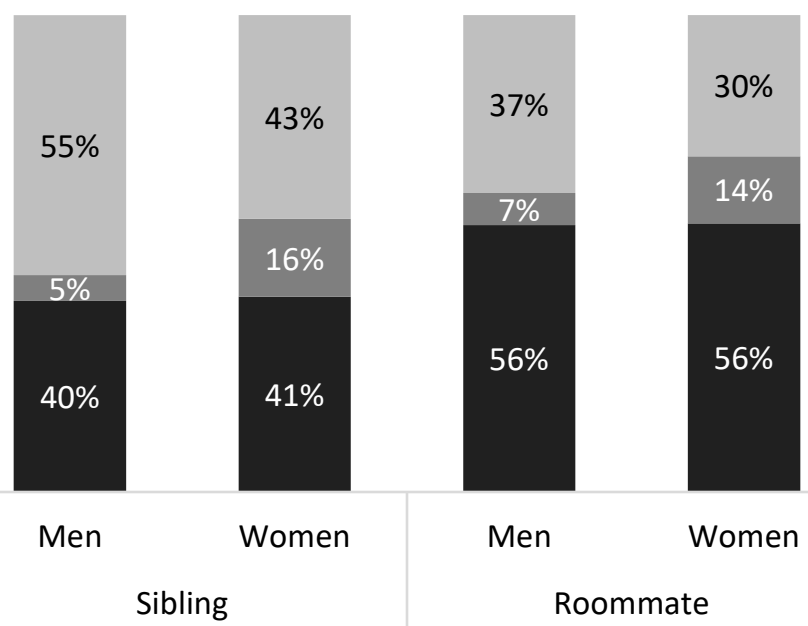

Source: NCFMR analyses of U.S. Census Bureau, Decennial Census, 1990; U.S. Census Bureau, American Community Survey, 2016 (IPUMS)

Figure 4. Poverty Status by Gender, 2016

$$
\text { Men Women }
$$

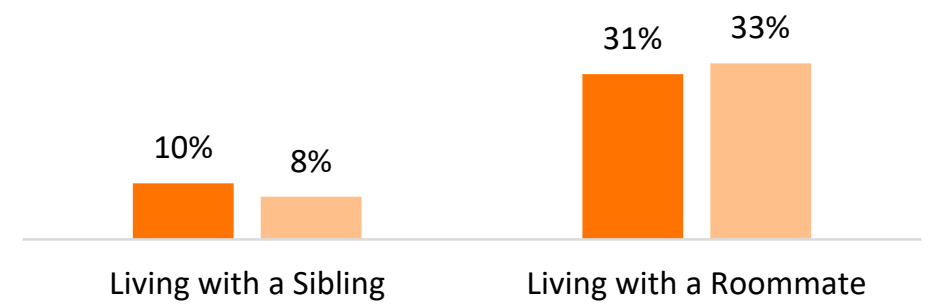

Source: NCFMR analyses of U.S. Census Bureau, Decennial Census, 1990; U.S. Census Bureau, American Community Survey, 2016 (IPUMS)

\section{References:}

Ruggles, S., Flood, S., Goeken, R., Grover, J., Meyer, E., Pacas, J., \& Sobek, M. (2018). IPUMS USA: Version 8.0 [dataset]. Minneapolis, MN: IPUMS. https://doi.org/10.18128/D010.V8.0

\section{Suggested Citation:}

Wu, H. (2018). Living with a sibling or roommate in older adulthood, 1990 \& 2016. Family Profiles, FP-18-19. Bowling Green, OH: National Center for Family \& Marriage Research. https://doi.org/10.2503 